\title{
FORMAS LINGUÍSTICAS INOVADORAS NÃO CONHECEM FRONTEIRAS: nós/a gente na fala da população da Costa da Lagoa
}

\author{
INNOVATIVE LINGUISTIC FORMS DON'T HAVE BOUNDARIES \\ nós/a gente in the speaking of the Costa da Lagoa people
}

Marizete Bortolanza Spessatto

Doutoranda em Educação-UFSC

\section{Resumo}

Trataremos, neste artigo, de um fenômeno de variação linguística que está se solidificando no português brasileiro: a inserção da expressão a gente no sistema pronominal do português, concorrendo com o pronome nós. O fenômeno não é recente. Porém, o que este artigo pretende mostrar, é que o emprego de a gente no vernáculo está se tornando comum mesmo entre grupos etários mais velhos e em contextos geográficos mais isolados, como é o caso da Costa da Lagoa, uma comunidade da ilha de Florianópolis-SC à qual se chega apenas a pé ou de barco e na qual os dados para análise neste artigo foram coletados. A pesquisa, embasada nos pressupostos teóricometodológicos da sociolingüística variacionista, tem como objetivo analisar a interferência de fatores sociais na utilização da forma inovadora na fala espontânea, além de averiguar quais os contextos linguísticos que mais favorecem o uso de a gente, em posição de sujeito.

Palavras-chave: Sociolinguística. 'Nós'/'a gente'. Gramaticalização.

\begin{abstract}
In this article, we will treat of a linguistic variation phenomenon which is getting stronger in Brazilian Portuguese: the insertion of the expression a gente in the Portuguese pronominal system that competes with the use of the pronoun nós. This is not a recent phenomena, however, what this article intends to show is that the use of $a$ gente is getting common even in the oldest age groups and in the more isolated geographic contexts, such as the case of Costa da Lagoa, a community of the Florianópolis Island, which it is only accessed by boat or walking across the coast, where the data analyzed in this article were collected. This research, embedded in the theoretical framework and methodological assumptions of the Sociolinguistics research, has the purpose to analyze the social factors interference in the use of this innovator form in the ordinary conversation, and to verify in which linguistic contexts the use of $a$ gente is more favored in the subject position.
\end{abstract}

Keywords: Sociolinguistic. 'Nós'/'a gente'. Grammaticalization.

\section{COMO SE CHEGA LÁ? O PERCURSO DE ACESSO AO LOCAL E AS QUESTÕES LINGUÍSTICAS}

Chove uma chuva fina e contínua. Na cidade o trânsito congestiona. As buzinas avisam da impaciência dos motoristas diante da demora em chegar em casa, na tarde de sábado. 
São mais de quatrocentos mil habitantes que dividem o espaço urbano que vem do continente à ilha. O cinza do céu se mistura ao cinza do asfalto e com a cor fosca das pinturas apagadas dos edifícios antigos. Passamos pela área central e vamos percorrendo os caminhos montanhosos que levam a uma das regiões mais badaladas no verão. O cenário se transforma: o cinza do céu encosta no cinza do mar, contrastando com o verde escuro das matas que ainda resistem à invasão de pessoas provenientes de vários lugares do país e até do mundo que escolheram o lugar para viver.

Não paramos aí. O carro, sim, esse fica. É preciso esperar o barco que de hora em hora assegura os moradores da Costa da Lagoa o acesso às suas casas. É inverno. O fluxo dos turistas, que há poucos anos descobriram a singularidade do lugar, é raro. No barco, apenas uma moça que ao sentar abre um caderno e faz anotações ao longo do percurso. Mais uma ou duas meninas que, pelo uso do uniforme, indicam retornar de uma atividade escolar e uma senhora que tenta, na medida do possível, fazer com que as sacolas com compras do supermercado não rolem para muito longe do lugar no qual está sentada.

O barco vai percorrendo a costa. Os edifícios há muito já deram adeus e em seu lugar vão aparecendo as casas penduradas nos morros, entre as árvores. $\mathrm{O}$ silêncio começa a se fazer ouvir, disputando espaço apenas com os motores da embarcação, único meio de transporte que dá acesso à costa. Começo a conversar com a senhora, mudando de lugar para ficar mais próxima a ela. Descubro que vive no ponto 19 (as comunidades são conhecidas pela numeração dos pontos de parada dos barcos), quase no final da costa. Explico que estou fazendo uma pesquisa na região. Recebo o convite para ir à sua casa. Depois de quase uma hora de percurso, ela abre a porta da residência e se abrem, com ela, as portas para a investigação que aqui se apresenta.

A partir da análise dos depoimentos de oito moradores da comunidade, divididos pelos fatores sociais 'faixa etária' (mais jovens: de 15 a 35 anos vs. mais velhos: mais de 46 anos) e 'escolarização' (até o ensino fundamental completo vs. ensino superior), pretendemos analisar a presença do pronome inovador a gente, concorrendo com nós, na fala da população de descendência açoriana da Costa da Lagoa, em Florianópolis/SC, verificando a influência das variáveis externas controladas, bem como da variável interna 'concordância verbal', no uso desses pronomes na fala da população local.

Começamos por descrever o local e por apresentar uma breve história da comunidade, por partirmos do pressuposto de que os fatores sociais e os linguísticos estão intrinsecamente relacionados. Isso porque, à primeira vista, as questões geográficas, como a dificuldade de acesso ao local, e histórico-culturais, como a preocupação em manter as tradições locais, parecem-nos favorecer as restrições às variantes linguísticas inovadoras.

\section{NÃO QUEREMOS ESTRADA: A PREOCUPAÇÃO DOS MORADORES EM ASSEGURAR O "SOSSEGO" DO LUGAR}

A história da Costa é antiga. Colonizada por portugueses, o lugar alcançou prestígio nos séculos XVIII e XIX, pelo forte intercâmbio de mercadorias que ali eram produzidas e levadas para a Lagoa e outros núcleos do município de Florianópolis. Mais tarde, as dificuldades de acesso e o controle rigoroso nas edificações foram reduzindo o fluxo de 
pessoas na área. Hoje, segundo dados da prefeitura de Florianópolis, moram na Costa cerca de 700 pessoas.

Considerada um dos últimos redutos da cultura açoriana, a Costa da Lagoa teve toda sua área tombada pelo município como Área de Preservação Cultural e patrimônio Histórico e Natural de Florianópolis. O Decreto Municipal n. ${ }^{\circ}$ 247/86 tomba o local como Patrimônio Histórico e Natural do Município de Florianópolis ${ }^{1}$. Tradicionalmente um reduto de pescadores e rendeiras, com o passar dos anos a inclinação econômica do lugar foi se modificando.

Muitos dos moradores do lugar trabalham fora da Costa. Exercem funções no comércio e prestação de serviços ou no trabalho doméstico. Outra fonte de renda, que tem sido incrementada no próprio local, é o turismo. Os turistas foram chegando aos poucos e fizeram com que bares e restaurantes fossem se instalando à beira da lagoa, geralmente ao lado dos pontos de parada dos barcos. M., uma das informantes entrevistadas, fala com satisfação do sucesso do negócio, com o aumento do volume de turistas dos últimos anos:

A comunidade não dá conta. No verão nosso barzinho, lá, onde eu tenho o meu barzinho tem cinco ou seis pertinho um do outro. [...] No verão dá cem pessoas comendo por dia, que a gente não dá conta de atender todo mundo. (Informante 2, entrevista gravada em 30 de maio de 2009) $)^{2}$.

Os turistas são bem-vindos. Os novos moradores, que nos últimos anos, segundo depoimentos coletados na própria comunidade, deixaram suas casas, vindos especialmente de estados como São Paulo e Rio Grande do Sul, também o são. Porém, a receptividade a outras culturas para por aí. O sentimento de comunidade e a preservação dos costumes locais podem ser vistos já na chegada. Em cada ponto de barco, placas contam a história dos moradores mais antigos, todos de origem portuguesa, e marcam a preocupação em preservar a história. Por isso, acreditamos, a maioria é unânime em afirmar que uma estrada para dar acesso da Costa às outras comunidades não é bemvinda. Um abaixo-assinado circulou em anos anteriores, mas os moradores não aceitaram que fosse dada continuidade ao movimento.

Entre as razões apresentadas, está, especialmente, a preocupação em assegurar o sossego de viver em um local pelo qual não passam automóveis:

Porque eu acho que a gente vive mais - vive mais feliz sem estrada. [...] Não é que eu quero dizer que porque tem estrada vai roubar, mas eu quero dizer assim que a gente agora vive mais tranquilo porque tem um barco aqui de hora em hora. (Informante 1, entrevista gravada em 30 de maio de 2009).

O sentimento aparece, nos depoimentos coletados, como algo compartilhado e que

1 No decreto, fica tombada toda a encosta da margem Oeste da Lagoa da Conceição, desde a Ponta dos Araçás até a Ponta do Saquinho, e o caminho da Costa da Lagoa, totalizando 967, 5 ha. O caminho caracteriza-se por uma trilha que pode ser feita a pé, do início ao fim da Costa.

2 Parte das entrevistas que compõem o corpus desta pesquisa foram gravadas por nós, em 30 de maio de 2009. As demais fazem parte do banco de dados VARSUL. 
passa de uma geração para a outra. Mesmo os mais jovens e mais escolarizados optam por permanecer no local, muitas vezes trabalhando em outras comunidades:

Minha filha tinha o terreninho que o sogro dela deu para eles, mas ela disse "mãe, mais vale passar ... perder tempo de barco, de ônibus, que a minha casa está aberta, durmo a noite inteira sem me preocupar com nada, a minha menina está na rua brincando. Então mais vale a paz, a segurança, também, né? (Informante 1, entrevista gravada em 30 de maio de 2009).

Esses sentimentos descrevem a relação da comunidade com o local onde vive. $\mathrm{Na}$ seção a seguir, a partir da revisão da literatura que trata sobre o tema, relacionaremos esses dados sociais com um fenômeno de variação e mudança linguística que caracteriza o português brasileiro: a gramaticalização de a gente como pronome referente à primeira pessoa do plural.

\section{REVISÃO DE LITERATURA: A GRAMATICALIZAÇÃO/PRONOMINALI- ZAÇÃO DE A GENTE}

A forma a gente, originária do substantivo gente, passa a fazer parte do sistema pronominal do português como indicação de primeira pessoa do plural, em variação com o pronome nós. O processo é chamado de gramaticalização e, nesse caso, consiste na mudança de um sintagma nominal para um pronome. A gente integra-se ao sistema pronominal concorrendo com nós.

A palavra gente, originária do latim gens, serve para "nomear de forma coletiva, indeterminadora, mais ou menos geral, um agrupamento de seres humanos, identificados entre si por objetivos, idéias, qualidades, nacionalidade ou posição." (OMENA; BRAGA, 1996, p. 75) Na análise do processo histórico de gramaticalização da forma a gente, Lopes $(2007$, p.73) aponta para o seguinte processo: gente [nome genérico] $\rightarrow$ a gente [pronome indefinido $\rightarrow$ a gente [substituto virtual do pronome pessoal nós].

Em estudo diacrônico da gramaticalização de a gente, Lopes $(1999$, p. 07) identificou a presença do substantivo, tanto no singular quanto no plural, em textos do século XIII ao XV. A partir do século XVI, a forma singular foi ganhando terreno, e o plural entrou, gradativamente, em desuso, embora ainda se encontrem exemplos do tipo até o século XIX. A referência à primeira pessoa do plural só se dá mais recentemente. Omena e Braga (1996) observam que, com a gramaticalização, a gente passa à função de pronome de primeira pessoa do plural. $\mathrm{O}$ uso na primeira pessoa do singular é, segundo elas, "menos frequente e bastante impreciso".

Embora evidenciado como um fenômeno presente nos usos cotidianos, as gramáticas normativas recentes não tratam de forma precisa a forma a gente, como aponta Lopes (1999, p.08):

A classificação é, em geral, controvertida, pois ora consideram a gente como "fórmula de representação da $1^{\text {a }}$ pessoa" (Cunha \& Cintra, 1985:288), ora como forma de tratamento (Bechara, 1967:117; 
Almeida, 1985:172), ou ainda como pronome indefinido (Said Ali, 1971:116 e Melo, 1980:122), comentários apenas em notas de rodapé. $\mathrm{O}$ caráter genérico e globalizante que a gente herdou do substantivo gente levou diversos pesquisadores a analisar esse uso da forma como um recurso para indeterminar o sujeito (Rollemberg et alii; $1991 \mathrm{e}$ Cunha, 1993). Entretanto, não se pode, no atual estágio evolutivo, considerar a gente como pronome indefinido, mas sim como pronome pessoal, uma vez que, como aponta Nascentes (1953:170), nas classes incultas no Brasil, o verbo deixa de estabelecer a concordância formal para fazer concordância semântica com a primeira pessoa do plural, pois "a pessoa que está falando tem em mente a sua pessoa e as mais, com ela associadas": "a gente vamos hoje"; "a gente tínhamos de voltar”. (LOPES, 1999, p. 08).

O processo de gramaticalização tem um caráter contínuo e pressupõe, principalmente nos estágios iniciais, a coexistência entre valores/usos, ao lado dos antigos e a permanência de propriedades lexicais nas formas gramaticalizadas:

$\mathrm{Na}$ gramaticalização de gente (nome) a gente (pronome) ocorre o mesmo. Nem todas as propriedades formais do nome gente foram perdidas, assim como não foram assumidas todas as propriedades intrínsecas aos pronomes pessoais. A forma gramaticalizada mantém do nome gente o traço formal de 3a pessoa, embora acione uma interpretação semântico discursiva de 1a pessoa [+EU]. Mesmo que o verbo em concordância com a gente permaneça na 3a pessoa do singular, se pressupõe a existência de um "falante + alguém", numa frase do tipo a gente precisa comprar a nossa própria casa. Tal comportamento remete-nos ainda ao princípio da decategorização (Hopper, 1991) que consiste na neutralização das marcas morfológicas e propriedades sintáticas da categoria-origem (nome) e adoção dos atributos da categoria-destino (forma pronominal). (LOPES, 2007, p. 52).

De acordo com Lopes (2007), a entrada de você e a gente gerou a reestruturação do sistema pronominal, criando novas possibilidades combinatórias. No caso do uso do você, com "a fusão do paradigma de 2 a com o de 3 a pessoa do singular e com a eliminação do paradigma de segunda pessoa do plural" (LOPES, 2007, p. 47-48). Uma importante reestruturação se dá com a redução nas flexões verbais, que com a entrada dos novos pronomes passa de seis para três formas básicas (eu falo, você/tu/ele/a gente fala, vocês/eles falam).

A introdução de a gente no sistema pronominal acarretou, por seu turno, um rearranjo no sistema pronominal tanto no subsistema de possessivos, quanto nos pronomes que exercem função de complemento diretos ou indiretos. Omena (2003, p. 65 apud LOPES, 2007) afirma que "a gente avançou mais em alguns contextos do que em outros". Segundo a autora, (preposição + a gente $=$ com a gente) tem emprego quase categórico entre as crianças no lugar de conosco. "Na função de complemento e de sujeito, com taxas diferentes entre crianças e adultos, a gente predomina." Em contrapartida, na variação de da gente, como adjunto adnominal, e o possessivo nosso (a)(s), há predomínio da forma conservadora (nosso e variantes) (OMENA, 1996, p. 190-1 apud LOPES, 2007). 
Os dados da autora mostram que, nos anos 90 e nos anos 2000, o uso de a gente passou de $75 \%$ para $79 \%$ na fala carioca, mostrando o avanço do uso da forma inovadora entre os falantes cultos e a estabilidade no uso entre os falantes não-cultos. De acordo com a amostra do NURC (coleta da fala carioca nos anos 70), a forma nós predominava sobre a forma inovadora entre os falantes cultos, o que já não ocorre com os percentuais das amostras do ano 2000. Em relação à variável 'faixa etária', dados do NURC (cf. LOPES, 2007) mostram um crescimento no uso de a gente entre os informantes mais jovens, passando de $81 \%$ para $92 \%$ entre os informantes cariocas de 25 a 35 anos.

Ao estudar os usos de a gente e nós na posição de sujeito, em informantes das cidades gaúchas de Jaguarão e Pelotas, Borges (2004) chegou a percentuais de uso de a gente de $78 \%$ na cidade de Pelotas, cidade polo da região, mais próxima da capital gaúcha, e de $69 \%$ em Jaguarão, fronteira com o Uruguai. Comparando os dados das duas cidades, o autor aponta que em Pelotas o uso de a gente vem "de cima para baixo", mais usado pela classe média alta e pelos homens, numa situação de "prestígio aberto", o que contribui para que os percentuais de uso sejam superiores aos de Jaguarão. O processo de gramaticalização de a gente está em estágio mais adiantado em Pelotas do que em Jaguarão, segundo o autor.

\section{ANÁLISE DOS DADOS: OS CAMINHOS DA COSTA SE CRUZAM COM OS CAMINHOS DE A GENTE}

Os moradores da Costa são unânimes em afirmar: quem nasce e cresce no lugar dificilmente se habitua a morar fora dele. Em uma capital com mais de quatrocentos mil habitantes e que dobra o número de habitantes no período do verão, a Costa não parece pertencer ao lugar. Sem o barulho dos veículos ou de uma multidão que congestiona os calçadões do centro da cidade, nas trilhas que servem como estradas na Costa ouve-se o cantar dos passarinhos. O apreço ao lugar é perceptível nas falas dos moradores de diferentes faixas etárias e níveis de escolarização.

Eles estão aqui representados pelo grupo de sujeitos participantes da pesquisa, assim distribuídos:

QUADRO 1: Distribuição dos informantes de acordo com as características sociais

\begin{tabular}{c|c|c}
\hline Idade/Escolaridade & Até Ensino Fundamental completo & Educação Superior \\
\hline de $\mathbf{1 5}$ a $\mathbf{3 5}$ anos & 1 & 2 \\
\hline acima de $\mathbf{4 6}$ anos & 2 & 1 \\
\hline Total & 3 & 3 \\
\hline
\end{tabular}

A distribuição não é homogênea em relação à variável social 'escolaridade', considerando o fato de termos encontrado poucos sujeitos mais velhos com mais escolarização e poucos sujeitos mais jovens menos escolarizados. Temos, então, na variável 'faixa etária' o principal fator social para análise, também apontado como um dos mais significativos em pesquisas que investigam o fenômeno.

O que une os sujeitos participantes desta pesquisa? O fato de viver na Costa não por falta de alternativa, como ocorre em muitos locais ou, então, de forma inconformada 
com as condições vividas, como ocorre em tantos outros. Ao contrário, as opiniões reveladas pelo grupo expressam a convicção de estar em "[...] um lugar muito bom para se viver. Eu não trocaria aqui por nada. Uma casa maior do que for, melhor do que tudo, eu não trocaria isso aqui por nada", afirma veementemente a entrevistada 1, uma senhora de 50 e poucos anos, com escolarização primária. Com curso superior completo, quarenta anos de idade, a entrevistada 3 também reforça o desejo de permanecer no local. Ao ser perguntada sobre as razões pela quais gosta de viver no local, ela assegura: "A paz. Tem muita gente que tá vindo morar aqui, mas tem ainda o convívio de família. A Costa é uma família, na verdade". Também graduada, porém mais jovem, a informante 4 reforça a vontade de viver no lugar: "Daqui eu não saio por nada mesmo. [...] a minha vontade é tá sempre aqui, não tenho vontade de ir para outro lugar." Com perfil diferente: 17 anos de idade e ensino fundamental incompleto, reclama apenas de uma coisa na Costa: "Um campo de futebol aqui na Costa, só isso já basta".

Pela voz dos entrevistados para a realização desse artigo, revela-se o sentimento que une o grupo. Uma comunidade assim, com tradições que sobrevivem aos tempos e se revelam nas rendas, nas cantigas de roda que vêm dos mais antigos e ainda se fazem ouvir nas brincadeiras da escola, nada mais natural do que pensar que formas linguísticas inovadoras no português brasileiro não se fizessem presente com tanta intensidade quando nos grandes centros, onde as trocas são mais constantes, intensas e vistas com mais naturalidade. Porém, não é o que ocorre com a forma inovadora $a$ gente.

No falar espontâneo do grupo de entrevistados, que recorda as dificuldades do passado, os desejos de uma vida tranquila para os filhos ou explicita as razões de gostar de viver no local, é a gente que toma o papel de sujeito. Os percentuais de uso da forma inovadora a gente entre a população entrevistada da Costa da Lagoa se comparam ao avanço do uso do pronome inovador apontado em estudos de grandes centros brasileiros, como o Rio de Janeiro (cf. dados de LOPES, 2007, aqui já apresentados). Das produções em primeira pessoa do plural, em contexto linguístico de sujeito, coletadas entre os sujeitos envolvidos nesta pesquisa, $72 \%$ são de a gente, contra $27 \%$ de nós.

\subsection{Influência dos condicionadores sociais na produção de a gente e nós}

Como já apontamos anteriormente, os sujeitos entrevistados para a realização desta pesquisa nasceram e residem na Costa da Lagoa, uma comunidade da ilha de Santa Catarina a qual se chega apenas a pé ou de barco. Entre as variáveis externas controladas (idade, escolaridade e indivíduo) o programa estatístico GOLDVARB2001 selecionou como significativa apenas a produção de cada indivíduo nos usos de a gente e de nós. Apresentaremos, no entanto, os resultados percentuais para as três variáveis, por julgarmos relevantes para a discussão proposta neste artigo.

Analisando a interferência da variável 'faixa etária', percebe-se uma proximidade bastante alta nas frequências de uso de a gente entre os dois grupos etários aqui analisados, conforme mostra a tabela 1 . 
TABELA 1: O uso de a gente e nós e a variável 'faixa etária'

\begin{tabular}{l|cc|cc|cc}
\hline Faixa Etária & \multicolumn{2}{|c|}{ A gente } & \multicolumn{2}{c|}{ Nós } & \multicolumn{2}{c}{ Total } \\
\hline $\mathbf{1 5}$ a 35 anos & 90 & $70 \%$ & 38 & $29 \%$ & 128 & $43 \%$ \\
\hline Acima de 46 anos & 123 & $74 \%$ & 42 & $25 \%$ & 165 & $56 \%$ \\
\hline Total & 213 & $72 \%$ & 80 & $27 \%$ & 293 & $100 \%$ \\
\hline
\end{tabular}

O uso de a gente entre os informantes de faixa etária mais alta é superior aos de faixa etária mais baixa, porém, em um percentual pouco significativo, 74\% para os informantes acima de 46 anos e $70 \%$ para os com menos de 35 anos de idade. Em contrapartida, são os informantes mais jovens que usam mais a forma nós, com $29 \%$ das ocorrências, contra $25 \%$ dos informantes acima de 46 anos.

Tínhamos como hipótese inicial, considerando estudos anteriores, especialmente de Omena (1986) e Fernandes e Görski (1986), que a substituição de nós por a gente estaria mais presente entre os informantes mais jovens. A hipótese, porém, não se verificou.

Embora, como já apresentamos anteriormente, não tenhamos o mesmo número de informantes mais e menos escolarizados, em cada uma das faixas etárias controladas, julgamos importante avaliar os resultados apontados pela análise estatística em relação à distribuição das ocorrências entre os sujeitos mais escolarizados, com nível superior completo, e menos escolarizados, com menos de oito anos de escolarização. É o que mostra a tabela 2 .

TABELA 2: Uso de a gente e nós e a variável 'escolaridade'

\begin{tabular}{l|cc|cc|cc}
\hline Escolaridade & \multicolumn{2}{|c|}{ Agente } & \multicolumn{2}{c|}{ Nós } & \multicolumn{2}{c}{ Total } \\
\hline Menos escolarizados & 87 & $61 \%$ & 54 & $38 \%$ & 141 & $48 \%$ \\
\hline Mais escolarizados & 126 & $82 \%$ & 26 & $17 \%$ & 152 & $51 \%$ \\
\hline Total & 213 & $72 \%$ & 80 & $27 \%$ & 293 & $100 \%$ \\
\hline
\end{tabular}

Os estudos que investigam a entrada de a gente no sistema pronominal do português brasileiro indicam que ele se expande "de baixo para cima" (cf. LOPES, 2007). Os dados coletados no desenvolvimento desta pesquisa mostram, por outro lado, que a forma inovadora está presente de forma mais intensa entre os informantes mais escolarizados do que entre aqueles que têm um nível de escolarização mais baixo. As diferenças percentuais são bastante significativas: a gente aparece em $82 \%$ das ocorrências entre os sujeitos mais escolarizados, contra $61 \%$ entre os menos escolarizados. São os informantes menos escolarizados os que mantêm um percentual mais alto de uso da forma antiga, nós, com $38 \%$ do total de ocorrências, contra $17 \%$ das ocorrências de nós, presentes na fala dos mais escolarizados.

A distribuição das ocorrências de a gente e nós por informante encontra-se na Tabela 3.

A análise da Tabela 3 nos mostra que o uso de a gente é bastante significativo nos dados dos informantes 6 ( $92 \%$ dos usos) e 4 ( $89 \%$ dos usos). Por outro lado, o uso de nós é 
quase categórico no informante 5 (96\% das ocorrências).

Analisando cada um dos sujeitos, individualmente, vimos, nos dados das informantes 6 e 4, que foram as que mais produziram a gente em contextos de primeira pessoa do plural; essas duas informantes pertenciam ao grupo de faixa etária mais baixa (entre 15 e 35 anos) e mais escolarizada; ambas tinham formação superior completa. Eram filhas de moradores nativos da Costa, estudaram na escola da comunidade durante a infância e cursaram universidade saindo de casa pela manhã e retornando à noite.

TABELA 3: O uso de a gente e de nós na produção de cada informante

\begin{tabular}{l|cc|cc|cc}
\hline Informantes & \multicolumn{2}{|c|}{ A gente } & \multicolumn{2}{c|}{ Nós } & \multicolumn{2}{c}{ Total } \\
\hline $\begin{array}{l}\text { Informante 1 } \\
\text { (F/fund/+46) }\end{array}$ & 50 & $79 \%$ & 13 & $20 \%$ & 63 & $21 \%$ \\
\hline $\begin{array}{l}\text { Informante 2 } \\
\text { (F/fund/+46) }\end{array}$ & 36 & $75 \%$ & 12 & $25 \%$ & 48 & $16 \%$ \\
\hline $\begin{array}{l}\text { Informante 3 } \\
\text { (F/sup/+46) }\end{array}$ & 37 & $68 \%$ & 17 & $31 \%$ & 54 & $18 \%$ \\
\hline $\begin{array}{l}\text { Informante 4 } \\
\text { (F/sup/15-35) }\end{array}$ & 42 & $89 \%$ & 05 & $10 \%$ & 47 & $16 \%$ \\
\hline $\begin{array}{l}\text { Informante 5 } \\
\text { (M/fund/15-35) }\end{array}$ & 01 & $3 \%$ & 29 & $96 \%$ & 30 & $10 \%$ \\
\hline $\begin{array}{l}\text { Informante 6 } \\
\text { (F/sup/15-35) }\end{array}$ & 47 & $92 \%$ & 04 & $7 \%$ & 51 & $17 \%$ \\
\hline Total & 213 & $72 \%$ & 80 & $27 \%$ & 293 & $100 \%$ \\
\hline
\end{tabular}

Embora o programa estatístico não tenha selecionado o grupo de fatores 'escolaridade' entre os mais significativos para os usos de a gente, as duas informantes que mais utilizaram esse pronome na função de sujeito estão nesse nível de escolarização. Ao analisar a presença de nós e a gente na fala florianopolitana (dados do VARSUL), Seara (2002) também encontra mais a produção da forma inovadora, em detrimento da forma nós, entre os informantes mais escolarizados (ginasial). No caso das informantes desta pesquisa, os usos podem ser justificados pela convivência em ambiente universitário e, especialmente, com sujeitos de diferentes centros urbanos que frequentam as universidades da capital do estado.

Por outro lado, o informante que mais utiliza a forma nós não concluiu a sétima série do Ensino Fundamental. Com 17 anos de idade, desistiu de estudar e trabalha como auxiliar de pedreiro na própria Costa. Das 30 produções com emprego de pronome de primeira pessoa do plural produzidas durante a entrevista, 29 foram de nós e apenas uma de a gente. É preciso considerar, entretanto, que, em algumas produções, a forma nós veio acompanhada por verbo sem a flexão de primeira pessoa do plural, em casos como "Nós pegava o barquinho..." e "Nós tem que pegar no correio."

O fato de ser um informante jovem contraria a hipótese inicial que tínhamos, de que os falantes mais jovens empregariam mais a forma inovadora. Segundo Omena (1986), "[...] a forma inovadora está se sobrepondo à padrão em todas as faixas etárias, com 
maior intensidade entre os jovens, e, em menores proporções, entre os adultos" (FERNANDES, 2004, p. 153).

\subsection{Influência dos condicionadores linguísticos na produção de a gente e nós}

Para a análise dos condicionadores internos, consideramos a possível interferência das seguintes variáveis linguísticas: 'preenchimento do sujeito', 'concordância verbal', 'saliência fônica' e 'paralelismo formal'. Submetidos os dados ao programa estatístico GOLDVARB2001, mostraram-se significativas as variáveis 'paralelismo formal' e 'concordância verbal'.

No caso do paralelismo formal, tanto o pronome a gente como o pronome nós levam sistematicamente a novas produções com a mesma forma, explícita ou apagada, como se observa em:

(1) A gente corria, Ø sentava em cima de uma pedra, Ø chupava cana (Informante 1)

(2) Nós fazia polvilho, com o meu pai, nós fazia, nós secava o polvilho pra nós fazer broa tudo lá no engenho do meu avô. (Informante 2)

Nas orações absolutas, há $70 \%$ de a gente e $29 \%$ de nós, como nos exemplos:

(3) A gente começou a fazer comida, um camarão frito. (Informante 2)

(4) Na verdade, nós temos uma pousada, né? (Informante 3)

A Tabela 4, a seguir, mostra os resultados relativos à variável 'concordância verbal'.

TABELA 4: Uso de a gente e nós e a variável 'concordância verbal'

\begin{tabular}{l|rc|rc|cc}
\hline Concordância verbal & \multicolumn{2}{|c|}{ A gente } & \multicolumn{2}{c|}{ Nós } & \multicolumn{2}{c}{ Total } \\
\hline Concordância & 213 & $100 \%$ & 59 & $74 \%$ & 272 & $93 \%$ \\
\hline Não concordância & 0 & $0 \%$ & 21 & $26 \%$ & 21 & $7 \%$ \\
\hline
\end{tabular}

De acordo com os resultados da tabela, há uso categórico de concordância verbal canônica com o sujeito a gente, como em:

(5) A gente sabe se vai chover pelo céu, né? (Informante 5)

A situação se modifica com o pronome nós, contexto em que se verifica $21 \%$ de não concordância, um percentual relativamente alto. A construção de orações com não concordância se observa com o uso de nós como sujeito explícito, em casos como:

(6) Ah, nós se reunia muito, é! (Informante 1)

(7) Nós pegava o barquinho aqui quinze para o meio dia, chegava na Lagoa a uma, aí saía às cinco e quinze do colégio, pegava o barquinho às cinco e meia.(Informante 5)

(8) Nós tem que pegar no correio, né? (Informante 5)

(9) Nós vendia para comprar uma roupinha pra nós assim. (Informante 2) 


\section{CONSIDERAÇÕES FINAIS}

A análise da significativa presença da forma inovadora a gente na fala da população da Costa da Lagoa ajuda a comprovar a hipótese, já apresentada em diversos estudos que analisam o fenômeno, de que vivemos uma mudança no sistema pronominal do português brasileiro. Ao mesmo tempo em que os moradores do lugar procuram preservar seus costumes e modo de vida das influências de outros grupos étnicos, culturais e econômicos, incorporam na fala um fenômeno de variação inovador.

Embora o programa estatístico não tenha considerado variáveis sociais relevantes, além do uso de cada informante, individualmente, uma questão importante e que precisa ser considerada é o fato de que a forma inovadora aparece mais na fala dos sujeitos com mais escolarização do que naqueles que estudaram menos. Para analisar o fato, é preciso considerar que os mais escolarizados também são aqueles moradores da Costa que mais tempo passaram fora dela, estudando no centro da cidade ou em cidades vizinhas, como São José. Locomovendo-se de barco ou mesmo a pé, em longos percursos, esses sujeitos estabeleceram contatos com falantes de outras variantes do português, no ambiente universitário, o que pode ter levado à incorporação da forma inovadora em seu vernáculo.

Com esses dados, aproximamo-nos das constatações a que chega Borges (2004) quando, no comparativo entre os usos de nós e a gente em duas cidades gaúchas, percebe que a forma inovadora é mais presente em Pelotas, por seus contatos com centros maiores, presença de duas universidades e duas escolas técnicas profissionalizantes que trazem estudantes de todo o país. Dessa forma, ao contrário de Jaguarão, os moradores de Pelotas estão mais expostos à diversidade linguística, do mesmo modo que ocorre com os moradores que estudam em universidades, fora da Costa.

Assim, a forma inovadora foi se incorporando à fala dos chamados "manezinhos da ilha", reconhecidos pelo falar "cantadinho". Quando questionados sobre o que caracteriza a fala da população local, os sujeitos consideram que "é diferente, principalmente na primeira vez que a gente sai [daqui]", afirma a entrevistada 6, afirmando ouvir dos interlocutores de outros municípios: "Como tu fala engraçado"! Independente dos deboches, também pela fala encontramos unidade entre os habitantes da Costa da Lagoa. Ao avaliar a fala do grupo, o informante 5 sintetiza: "O nosso falar, o nosso jeito de vestir, mais manezinho da ilha é mais no falar. Eu tenho orgulho".

\section{REFERÊNCIAS}

FERNANDES, E. A. Fenômeno variável: nós e a gente. In: HORA, Dermeval da.. (Org.). Estudos lingüísticos: perfil de uma comunidade. João Pessoa: UFPB, 2004.

FERNANDES, E.; GORSKI, E. A concordância verbal com os sujeitos Nós e A gente: um mecanismo do discurso em mudança. In: Atas do I Simpósio sobre a Diversidade Lingüística no Brasil. Salvador, Instituto de Letras da UFBA, p.175-83, 1986.

LOPES, C. R. S.. A inserção de a gente no quadro pronominal do português: percurso histórico. Rio de Janeiro: UFRJ, Faculdade de Letras, 1999. (Tese de Doutorado em Língua Portuguesa). 
. A gramaticalização de a gente em português em tempo real de longa e de curta duração: retenção e mudança na especificidade dos traços intrínsecos. Florianópolis: Fórum Linguístico. v. 4, n. 1 (47-80), julho de 2007.

MACEDO, A. T., RONCARATI, C. e MOLLICA, M. C. (org.): Variação e Discurso. Rio de Janeiro, Tempo Brasileiro, 1996.

OMENA, Nelize Pires de; BRAGA, Maria Luiza. A gente está se gramaticalizando? In.: MACEDO, A. T., RONCARATI, C. \& MOLLICA, M. C. (org.): Variação e Discurso. Rio de Janeiro, Tempo Brasileiro, 1996.

. Projeto subsídios sociolingüísticos do projeto censo à educação. V. II. Relatório final apresentado ao FINEP, OUT/1986.

SEARA, I. C.. A variação do sujeito nós e a gente na fala florianopolitana. Porto Alegre: Organon (UFRGS), v. 14, n. 28/29, p. 179-194, 2002. 